\title{
Biomarkers of teratogenesis: Suggestions from animal studies
}

\author{
Erminio Giavini*, Elena Menegola \\ Università di Milano, Department of Biology, Italy
}

\section{A R T I C L E I N F O}

\section{Article history:}

Received 1 March 2012

Received in revised form 3 May 2012

Accepted 10 May 2012

Available online 18 May 2012

\section{Keywords:}

Biomarkers

Teratogenesis

Mechanisms

\begin{abstract}
A B S T R A C T
Biomarkers of effect are measurable biochemical, physiological or other alterations within an organism that can be recognized as causing an established or potential impairment of embryo-fetal development. They may be identified studying the mechanisms of action of teratogens. Hyperacetylation of histones, oxidative stress, cholesterol and retinoic acid unbalance are some of the identified mechanisms of action of some known teratogens. Nevertheless, their use is not currently applicable in human pregnancy because of the difficulty of the choice of biological material, the time when the material must be obtained, and the invasivity of methods. Furthermore, before using them in human pregnancy studies, biomarkers should be validated in experimental animals and in epidemiologic studies. On the contrary, some biomarkers could be useful in the screening of developmental toxicity of chemicals and drugs, comparing molecules of the same chemical class or with the similar pharmacologic activity, and using adequate in vitro tests, in order to reduce the use of experimental animals.
\end{abstract}

(c) 2012 Elsevier Inc. All rights reserved.

\section{Introduction}

According to the Committee on Developmental Toxicology of National Research Council [1], three types of biomarkers in reproductive toxicology can be defined: (1) biomarkers of exposure, defined as a xenobiotic or its metabolite(s) measurable in a compartment within an organism; (2) biomarkers of effect, that represent measurable biochemical, physiological, or other alterations within an organism that can be recognized as causing an established or potential impairment of embryo-fetal development; (3) biomarkers of susceptibility, i.e. indicators of an inherent or acquired limitation of an organism's ability to respond to the challenge of exposure to a specific xenobiotic.

In this paper we try to extrapolate from experimental studies some suggestions for identifying molecular markers of developmental toxicity. The basic idea is that a teratogen may induce its detrimental effects altering something in the machinery which controls the normal embryonic development. As a consequence the easiest way to identify a specific biomarker is to study the mechanism of action of a teratogen. It is questionable if these biomarkers may be really useful for the prediction of pregnancy outcome.

\section{Mechanisms of teratogenicity}

In spite of the long time spent in research in this field, the knowledge of mechanisms of action of chemicals in inducing teratogenic

\footnotetext{
* Corresponding author. Tel.: +39 0250314753; fax: +39 0250314802.

E-mail address: erminio.giavini@unimi.it (E. Giavini).
}

effects is rather incomplete. However, for some chemicals a great deal of evidence has been gathered supporting certain aspects of the mechanisms. The reasons for the failure in a complete understanding of the mechanisms at work in chemically induced congenital malformations are almost dual: (a) first of all the complexity of the molecular mechanisms controlling the embryonic development. During the last 20 years enormous progresses have been made in the study of the molecular interactions controlling the different aspects of development (cell proliferation, cell migration, cell differentiation, cell death, etc.) but there are still many obscure points, and much has yet to be revealed; (b) the second point is, to some extent, a consequence of the first. It is likely that many teratogenic agents act through more than one embryotoxic mechanism of action, interfering with several mechanisms that control normal embryonic development. This can lead to multiple organ malformations, or only one organ may be malformed through many mechanisms acting simultaneously or separately.

On the basis of the nowadays knowledge the embryonic development may be simplified as a differential expression of specific genes in specific places and at specific times in the developing organism. These genes encode for transcription factors, i.e. proteins that are able to activate or repress the transcription of particular genes. Furthermore, for a precise coordination of developmental processes, interaction is need between cells and tissues through chemical signals: the growth and differentiation factors which activate or repress specific genes [2]. The gene expression is regulated not only by transcription factors, but also by other kind of molecules named morphogens able to diffuse along the organ axis and to modulate the expression of specific genes interacting with nuclear receptors. The activity of these morphogens is 
concentration related; that means that the embryo must be able to control the exact concentration of these molecules in specific organs. Retinoic acid is one of the best known morphogens [3].

\subsection{Hyperacetylation}

During the last decade a new family of drugs has been emerged as a new class of anticancer agents: histone deacetylase inhibitors (HDACi). HDACi are able to inhibit histone deacetylase enzymes inducing histone hyperacetylation. As the acetylation status of histones plays a crucial role in modulating chromatin structure and gene transcription, HDACi could interfere with the gene expression during embryonic development leading to congenital malformations. Chemicals as valproic acid (VPA), trichostatin A (TSA), apicidin, MS-275, and sodium butirate are known as HDACi. They have been described as able to induce embryonic histone hypercetylation [4-6] and axial skeletal malformations [4,7]. It is interesting to observe that other drugs able to induce axial skeletal malformations in animal models as sodium salicylate and boric acid have shown to be HDACi and to hypercetylate embryonic cells [8,9]; furthermore, carbamazepine, topiramate, and the major metabolite of levetiracetam (anticonvulsivants able to induce in humans congenital malformations), have been demonstrated to be HDACi in vitro $[10,11]$. So, the inhibition of HDAC and the consequent hyperacetylation of histones seem to be the mechanisms of action of VPA and other drugs and the histone hyperacetylation could represent a good biomarker for this group of chemicals. However, the axial skeletal malformations is a common malformation observed in all laboratory animals exposed in utero to VPA but never described in human babies exposed to VPA or other antiepileptic drugs. The most frequent congenital malformation induced by VPA in human conceptuses is spina bifida $[12,13]$ together with other kinds of malformations at the level of the face and other organs. In mice VPA is able to induce high frequencies of exencephaly and other kind of malformations including heart malformations. Wu et al. [14] were able to associate VPA-induced heart malformations in mice with HDAC inhibition but there are no data correlating exencephaly induced by VPA with HDAC inhibition.

On the other hand, VPA inhibiting HDAC and increasing histone acetylation stimulates DNA demethylation probably through facilitating access of regulatory regions of genes to demethylase [15-17]. Other hyperacetylating drugs are able to induce DNA demethylation. For example, TSA induces DNA demethylation in human cancer cell lines showing also some gene selectivity [18]; sodium butyrate was shown to trigger active demethylation of Epstein Barr virus and cellular DNA in human cells [19]. Recent data stand to reason that DNA demethylation could be responsible for teratogenic effects induced by VPA and other HDAC inhibitors. In fact, neural tube defects in some human population have been correlated to folic acid deficiency during early gestation which could result in a reduced methyl availability in embryonic cells and consequent hypomethylation of DNA [20]. Periconceptional and early gestational supplementation with folic acid strongly reduced the incidence of spontaneous spina bifida in human population $[21,22]$.

However, there is disagreement about benefit of folic acid in reducing the rate of NTD following VPA or other antiepileptic drug exposure $[23,24]$. Recently, Pittschieler et al. [25] reported a significant reduction of spontaneous abortion and premature delivery in women treated with VPA and carbamazepine after periconceptional folic acid supplementation. Folic acid or methionine supplementation were able to reduce the neural tube defects induced by VPA in some strain of mice [26-28] but not in other strains $[29,30]$ showing that the genetic background plays an important role in susceptibility to drug-induced congenital malformations.
The measure of global DNA methylation could be a biomarker of teratogenesis. Actually, global methylation assays define an average methylation and important changes involving increases in some regions coupled with decreases in other regions might not be detected if one simply looks at the average level of methylation [17]. New techniques finalized to identify specific demethylated genes could improve significantly this approach.

\subsection{Oxidative stress}

A number of xenobiotics can be bioactivated enzymatically (prostaglandine $\mathrm{H}$ synthase, lipoxigenese, cytochrome P450 are some involved enzymes) to electrophilic or free radical reactive intermediates. If not detoxified, electrophilic reactive intermediates can bind covalently to cellular macromolecules (DNA, proteins), while free radical reactive intermediates can react with molecular oxygen to initiate the formation of reactive oxygen species - ROS, (superoxide anion, $\mathrm{H}_{2} \mathrm{O}_{2}$, hydroxyl radicals). The ROS, if not detoxified by antioxidants or antioxidatives enzymes, may oxidatively damage cellular macromolecules such as lipids, proteins, RNA and DNA [31]. ROS are physiologically continuously generated by intracellular metabolism and the cells developed antioxidant defense mechanisms which include: enzymes as superoxide dismutase (SOD) that transfer superoxide radicals into hydrogen peroxide, catalase (CAT) and catalase like enzymes and glutathione like enzymes that decompose hydrogen peroxide; low molecular weight antioxidant (vitamin C, glutathione, vitamin E, flavonoids, etc.) which interact directly with ROS inhibiting their reactivity; enzymes able to repair or remove ROS-damaged macromolecules. The cellular anti-ROS machinery in normal conditions maintains a balance between ROS formation and detoxification. An imbalance between ROS production and antioxidant defense results in oxidative stress with consequent cellular damage and pathology. The early embryo seems to be particularly at risk for oxidative stress because expresses relatively low levels of most enzymes involved in the detoxification of reactive intermediates and ROS. Actually, the embryonic levels of most antioxidant enzymes are around only 5\% of maternal activity [31].

The anticonvulsant phenytoin is teratogenic in several animal models and in humans. In humans the classic feature characterizing the drug-induced malformations includes facial dysmorphia, hypoplasia of phalanges, growth retardation, orofacial cleft and cardiac anomalies. In laboratory animals the principal malformations described in rodents and rabbit include cleft palate, ectrodactyly, renal abnormalities, neural tube defects [32]. Several data indicate a role of oxidative stress in phenytoin-induced teratogenesis. It enhances embryonic and fetal levels of 7,8-dihydro-8-oxoguanine (commonly named 8-oxoguanine, 8-oxoG), one of the prevalent forms of oxidative DNA damage caused by hydroxyl radicals and also enhances the oxidation of GSH, proteins and lipids [33]. In an elegant series of experiments Abramov and Wells [34,35] were able to demonstrate the protective role of catalase against phenytoininduced DNA oxidation and embryopathies using both in vivo and in vitro approaches.

Several studies provided evidence suggesting a role for oxidative stress also in VPA-induced teratogenesis. In a whole embryo culture (WEC) model, Zhang et al. [36] showed that VPA increases oxidized/reduced GSH ratio and decreases total GSH content. Pretreatment with vitamin $\mathrm{C}$ reversed these effects. In vivo studies demonstrated that oral administration of $500 \mathrm{mg} / \mathrm{kg}$ vitamin $\mathrm{E} 1 \mathrm{~h}$ before treatment with $700 \mathrm{mg} / \mathrm{kg}$ VPA on day 8 of gestation in Balb mice significantly reduced the incidence of exencephaly and resorptions, and increased the fetal weight [37]. Tung and Winn [38] exposed mouse embryos in vitro and in vivo to teratogenic doses of VPA and to catalase (in vitro) or PGE-catalase (in vivo). Catalase was able to reduce the frequency of embryos with open 
neural tube at the end of the culture period and of fetuses with exencephaly at term of pregnancy. It is interesting to signal that increased levels of 8-oxoG have been reported in patients treated with VPA in mono or polytherapy [39,40].

Among the numerous mechanisms of teratogenic action attributed to Thalidomide (TD), recently oxidative stress emerged with good evidence. Lee et al. [41] cultured rabbit embryos in presence of TD or its metabolites obtaining otic vescicle and limb bud reduced formation associated with an increase of 8-oxoG by up two folds. Co- or pretreatment with prostaglandin $\mathrm{H}$ synthase inhibitors or free radicals spin trap completely blocked embryonic 8-oxoG formation and embryopathies induced by TD or its metabolites, indicating a ROS-mediated mechanism in TD-induced embryopathies.

Ethanol (Eth) consumption during pregnancy disrupts embryonic and fetal development in humans producing a well defined fetal alcohol syndrome characterized by growth deficiency, mental retardation, facial dysphormia (small palpebral fissures, hypoplastic philtrum, thin upper lip and micrognathia). Other anomalies such as cardiac defects, cleft lip/palate, limb abnormalities are also common [42-44]. Similar abnormalities have been obtained in several animal species exposed to ethanol during pregnancy [45]. The precise mechanism of action of Eth in inducing embryofetal anomalies have not been yet completely clarified, but there is growing evidence that oxidative stress may play an important role. Eth can induce oxidative stress directly or indirectly. The direct effect is due to formation of free radicals (hydroxyl and hydroethyl groups) able to react with various cellular components. Another direct oxidative stress effect induced by Eth is the formation of ROS [46]. Eth can also induce oxidative stress indirectly by reducing intracellular antioxidant capacity, e.g. the levels of glutathione peroxidase. Kotch et al. [47], using mouse WEC, demonstrated that Eth-induced teratogenesis may be related to free radical damage. The exposure of the embryos to $500 \mathrm{mg} \%$ Eth resulted in a high frequency of abnormal embryos, excessive cellular death and superoxide radical generation (determined using nitroblutetrazolium as a probe). The co-culture with SOD significantly reduced the incidence of embryonic abnormalities, cell death and superoxide formation. SOD also reduced the lipid peroxidation induced by Eth. Rat embryos were exposed in vitro to Eth or its main metabolite acetaldehyde (Ach) at increasing concentration levels. Both chemicals induced embryotoxicity in dose related manner and increased intracellular P-53 and 8-oxoG (measured in midbrain cells). Co-exposure with catalase significantly reduced the observed cytotoxic effects [48]. Wentzel et al. [49] exposed pregnant rats to Eth $20 \%$ in drinking water. Some animals received food supplemented with $5 \%$ vitamin E. Eth increased the frequency of resorptions and fetal malformations. Supplementation with vitamin E normalized the fetal development. Ach, the main metabolite of Eth, has been indicated as the proximate teratogen in Eth-induced malformations [50]. Menegola et al. [51] in a WEC study on rat embryos demonstrated that preexposure of the embryos to an inhibitor of GSH synthesis significantly enhanced the embryotoxic effects of Ach. On the contrary, coexposure to GSH or $\mathrm{N}$-acetylcysteine significantly reduced the frequency of abnormal embryos.

On the basis of experimental data, increased levels of ROS and/or 8-oxoG are good biomarkers of oxidative stress induced by different kinds of chemicals.

\subsection{Cholesterol unbalance}

Endogenous cholesterol synthesis starts from acetate in a series of enzymatic steps each of which can be inhibited. The knockout of some enzymes of this series in mouse resulted in early embryonic death [52], demonstrating the fundamental role of cholesterol synthesis for embryonic development.

First suspicion that cholesterol is essential for embryonic development and, specifically, for forebrain development came from an epidemic of holoprosencephaly (HPE) in lambs born to ewes that ate Veratrum californicum during pregnancy [53]. Two alcaloids extracted from Veratrum and purified (Jervine and Cyplopamine) were able to produce HPE when administered to ewes on the 14th day of gestation (gastrulation stage) [54]. Afterwards, experiments in rabbits, mice, rats, and hamsters revealed that also these species were susceptible to cyclopamine induced head malformations $[55,56]$. HPE is a malformation sequence in which impaired midline cleavage of the embryonic forebrain is the defining feature, but various gradation of facial dysmorphism are associated with HPE: the most severe forms include cyclopia, the less severe closely spaced eyes with or without cleft lip [57]. Some evidences led the scientists studying the cyclopamine mechanism of action to hypothesize interferences with cholesterol metabolism: (1) molecular structure similarity between cyclopamine and cholesterol, (2) the role of cholesterol in signal functionality of Sonic hedgehog (Shh), a signal protein essential for forebrain development, (3) mutations of Shh cause HPE in mice [58] and humans [59]. Further studies evidenced that Veratrum alkaloid-induced HPE is strictly related to inhibition of Shh signal transduction, but not through interference with cholesterol synthesis $[60,61]$. However, the role of cholesterol in the control of Shh signaling and face morphogenesis is nowadays clear. Hedgehog proteins need a covalent binding with cholesterol to generate the mature signal molecule [62]. Over the last couple of decades, a number of human malformation syndromes have been associated with defects in sterol synthesis (for exhaustive reviews see [52]). Smith-Lemli-Optiz syndrome (SLOS) was the first human syndrome discovered to be due to an inborn error of sterol synthesis [63]. The SLOS phenotype includes microcephaly, mental retardation, developmental delay, and distinctive facial features; cleft palate and syndactyly are common and structural brain malformations including HPE and abnormalities of corpus callosum can also be observed. The most severely affected fetuses die in utero during the perinatal period. SLOS is due to a mutation of DHCR7, which encodes for 7-dehydrocholesterolreductase, a key enzyme in the synthesis of cholesterol. Targeted disruptions of Dher7 gene have been generated in mouse by Fitzky et al. [64] and Wassif et al. [65]. All knockout pups were severely growth retarded and died within $24 \mathrm{~h}$ after birth, probably for asphyxia and failure to suckle. Some of them were affected by cleft palate and showed facial dysmorphia. Two specific inhibitors of DHCR7 (AY9944 and BM15766) are teratogenic in rat both in vivo and in vitro [66-68]. The most characteristic malformations in vivo are of the HPE types in about 25\% of fetuses, but $80 \%$ of the apparently normal fetuses had pituitary agenesis [69]. The administration of AY9944 on day 4 of gestation produces a significant decrease of cholesterol plasma levels on day 10 of gestation. Cholesterol supplementation can prevent specific malformations [70]. Similarly, Dehart et al. [71] obtained a high frequency of fetuses affected by head malformation mimicking HPE administering BM15766 to female rats on days 4-7 of gestation. The treatment was followed by a dramatic decrease of maternal plasma cholesterol and increase of 7-dehydrocholesterol. In vitro studies evidenced the role of the embryonic inhibition of cholesterol synthesis in the induction of malformations [67].

The Antley-Bixler syndrome (ABS) is characterized by brachycephaly, facial hypoplasia, bowed ulna or femur, synostosis of radius, and cardiac and urogenital abnormalities [72] related to heterogeneous pool of disorders in sterol metabolism. Two ABS case studies reported impaired CYP51 activity and a consequent increased levels of lanosterol [73]. Mice KO of Cyp51 die before day 15 of gestation. The embryo examination before death revealed malformations similar to those observed in ABS: micrognathia, 
shortened and bowed radius and ulna, femural-tibial synostosis, heart defects [74]. Azole fungicides (triazole and imidazole derivatives) act by competitive inhibition of Cyp51 that cause depletion of ergosterol and accumulation of lanosterol in fungal cells resulting in alterations of fungal wall and growth inhibition [75]. Fluconazole is a triazole antifungal agent used in human therapy. Five case reports have been reported about infants exposed in utero to Fluconazole with a pattern of malformations resembling ABS [76]. Fluconazole, as other azole fungicides used in human therapy and in agriculture, is teratogenic in laboratory animals producing craniofacial and axial skeleton defects [77-80].

\subsection{Retinoic acid unbalance}

Retinoic acid (RA), a metabolite of vitamin A, is a well-known morphogen in vertebrate and invertebrate embryos [81]. A direct relationship between RA concentration, Hox genes expression, and craniofacial, vertebral and limb morphogenesis has been well documented [82-85]. The first step in the synthesis of RA is the conversion of retinol to retinal, a reaction catalyzed by the alcohol dheydrogenase enzymes; the second step is the conversion of retinal to RA, oxidation mediated by aldehyde dehydrogenase enzymes. Catabolism of RA is controlled by the Cyp26 family enzymes (CYP26A1, B1, C1). Unbalance between synthesis and degradation of RA may result in excess or deficiency in RA concentration with deleterious effects on the affected cells. RA initiates gene transcription by acting as a ligand for the retinoic acid receptors into the nucleus. Specific proteins present in the cytosol (cellular retinoic acid binding proteins, CRABP) function as carriers to transport RA to the nucleus and as a buffer to decrease the concentration of free RA available to the nucleus. RA is able to control its own metabolism to a certain extent by eliciting up-regulation of Cyp26a1 in a negative autoregulatory feedback mechanism. Expression of Cyp26a1 is rapidly up-regulated upon RA treatment [86]. Similarly, CRABP-1 is up-regulated in mouse embryos exposed to excess of RA [87] probably acting as a buffer to decrease the concentrations of free RA available to the nucleus.

Chemicals able to inhibit the synthesis or the catabolism of RA may result in a deficiency or in an excess of the morphogen with deleterious effect for the embryo. Among the substances that compete with the enzymes of the synthesis there is Eth. Firstly, Pullarkat [88] and Duester [89] hypothesized that the structural abnormalities induced by Eth are due to diminished RA concentration which occur as a result of the competitive inhibition of RA synthetic enzymes by Eth. Indeed, it has been recognized that Eth is able to reduce RA concentrations in mammalian embryos [90]. Johnson et al. [91] demonstrated in an in vivo experiment on mouse that the excessive cell death induced by Eth in limb buds was prevented by RA supplementation. In experiments carried out on Zebra fish embryos, Eth $(100 \mathrm{mM})$ induced very severe malformations that were rescued by cotreatment with RA $10^{-9} \mathrm{M}$. Similar results were obtained by Yelin et al. [92] on Xenopus embryos.

On the other hand, chemicals able to inhibit CYP26 enzymes may be responsible of increased concentrations of RA. Some azole fungicides have been shown to be able to inhibit CYP26 enzymes in adult rats as well as in patients with acute promyelocytic leukemia $[93,94]$. In rat and mouse embryos azole fungicides are able to induce craniofacial and axial skeleton defects very similar to those induced by excess of RA [95-97]. Furthermore, in vitro and in vivo exposure of rodent embryos to azole fungicides results in an increase of expression of CRABP [96] and Cyp26 [97] signals of an increased concentration of RA. Similar effects have been reported in Xenopus embryos [98]. These results all together induce to suppose a likely interference of azole fungicides on RA catabolism in the induction of craniofacial and axial skeleton malformations.

\section{Discussion}

The majority of teratogenic agents are able to induce pleiotropic effects. For example, although TD is popularly known as the drug able to induce phocomelia, actually its teratogenic activity includes ear, heart, urogenital and nervous system abnormalities. Similarly, VPA, known to induce spina bifida in human children, is able to produce a wide range of malformations including craniofacial, cardiovascular, genital, limb and nervous system malformations [99]. It is possible that different malformations could be induced by the same mechanism of action. It is well known, for example, that interferences with Hox gene expression may be responsible of axial skeletal defects and craniofacial abnormalities because these genes control the morphogenesis of both these structures [81,83]. It is also likely to suppose that different organs could be affected by the same teratogen through different mechanisms of action. On the other hands, different proved mechanisms of action have been found for the same teratogen. VPA is certainly able to induce histone hyperacetylation and consequent DNA hypomethylation, but is also able to produce oxidative stress (several other mechanisms of action attributed to VPA are less convincing). Eth induces oxidative stress and is also implicated in reduced RA synthesis through competitive inhibition of alcohol and aldehyde dehydrogenase. The facial malformations induced by exposure to Eth have been also related to altered expression of Shh $[100,101]$, but this effect could be secondary to excessive cell death produced by other mechanisms, e.g. oxidative stress. Azole fungicides teratogenic effects may be explained both by inhibition of cholesterol synthesis or by inhibition of RA catabolism. In spite of the different mechanisms of action in act in the induction of a particular malformation, when a mechanism is adequately proved to be related to a teratogen, it may be considered a biomarker of effect: histone hyperacetylation may be a biomarker for antiepileptic drugs, 8-oxoG or ROS may be considered biomarkers for chemicals producing oxidative stress, cholesterol content may be a biomarker of chemicals which interfere with cholesterol synthesis.

\subsection{Limitations of the use of biomarkers of effect}

A valid biomarker should be (1) a stable product, (2) easily accessible via non invasive methods, (3) present at concentrations high enough to be a significant product, (4) measurable with an assay that is specific, sensitive, and reproducible, (5) measurable with relatively small within-assay intrasample variations in comparison with between-person variations. Furthermore, before using, biomarkers must be validated through multiple step procedures including validation of the method in experimental animals and in epidemiologic studies [102]. No biomarker of teratogenesis meets all these requirements. We are just initiating the first step: individuation of a suitable biomarker. It is very complicated the use of these biomarkers on human pregnancy to predict the effect on the conceptus. Actually, in order to identify biomarkers of effect it is important the choice of the biological material to be tested (e.g. chorionic villi, amniotic fluid) and the pregnancy time when the material must be obtained. The reason is that molecular alterations producing a biomarker of embryotoxicity are usually confined in a brief period of the embryonic development: before or after this period the test will not produce any result. In order to obtain predictive information on the outcome of gestation the contemporaneous use of biomarkers of exposure, biomarkers of effect, and biomarkers of susceptibility could be of great help. The biomarkers of exposure must include temporal data, as the gestational age at the time of exposure to the chemicals is fundamental in order to evaluate a cause-effect relationship. But the limits mentioned above make, in our opinion, the use of biomarkers of effect not currently applicable for the prediction of outcome in human pregnancy. However, 
they could be used in the identification of people at risk, with hopes of reducing the risk by modifying exposure and by developing other intervention strategies (for example, administration of antioxidants) to decrease the incidence of developmental defects.

\subsection{Use of biomarkers in developmental toxicity studies}

On the contrary, these kinds of biomarkers may be very useful in the screening of developmental toxicity of chemicals and drugs, comparing molecules of the same chemical class (e.g. triazoles) or with similar pharmacological activity (e.g. antiepileptics). The use of specific biomarkers would also permit to avoid expensive in vivo tests which may usefully be substituted by in vitro tests as WEC or cell cultures. For example, hyperacetylation of histones has been observed in cell cultures $[6,10,11]$, cholesterol unbalance has been observed in WEC [68], SOD and other oxidative stress biomarkers have been evaluated in WEC [34,38,47,51], WEC and Xenopus embryos have been used to demonstrate the increased expression of CRABP and Cyp26 after exposure to triazole fungicides $[96,98]$. These alternative methods, with the help of specific biomarkers, may be used to meet the three R (replacement, reduction, refinement) recommended by several regulatory agencies as a basis of a new approach of the animal welfare in the animal experiments.

\section{Conflict of interest statement}

The authors declare that there are no conflicts of interest.

\section{References}

[1] National Research Council. Scientific frontiers in developmental toxicology and risk assessment. Washington, DC: National Academic Press; 2001.

[2] Gilbert. Developmental biology 2003. Sunderland, USA: Sinauer Associates Inc.; 2005.

[3] Ross SA, McCaffery PJ, Grager UC, De Luca LM. Retinoids in embryonal development. Physiological Reviews 2000;80:1021-54.

[4] Menegola E, Di Renzo F, Broccia ML, Prudenziati M, Minucci S, Massa V, et al. Inhibition of histone deacetylase activity on specific embryonic tissues as a new mechanism for teratogenicity. Birth Defects Research Part B 2005;74:392-8

[5] Nervi C, Borello U, Fazi F, Buffa V, Pelicci PG, Cossu G. Inhibition of histone deacetylase activity by trichostatin $A$ modulates gene expression during mouse embryogenesis without apparent toxicity. Cancer Research 2001;61:1247-9.

[6] Phiel CJ, Zhang F, Huang EY, Guenther MG, Lazar MA, Klein PS. Histone deacetylase is a direct target of valproic acid, a potent anticonvulsant, mood stabilizer, and teratogen. Journal of Biological Chemistry 2001;276:36734-41.

[7] Di Renzo F, Broccia ML, Giavini E, Menegola E. Relationship between embryonic histonic hyperacetylation and axial skeletal defects in mouse exposed to the three HDAC inhibitors apicidin, MS-275, and sodium butyrate. Toxicological Sciences 2007;98:582-8.

[8] Di Renzo F, Cappelletti G, Broccia ML, Giavini E, Menegola E. Boric acid inhibits embryonic histone deacetylases: a suggested mechanism to explain boric acid-related teratogenicity. Toxicology and Applied Pharmacology 2007;220:178-85

[9] Di Renzo F, Cappelletti G, Broccia ML, Giavini E, Menegola E. The inhibition of embryonic histone deacetylases as the possible mechanism accounting for axial skeletal malformations induced by sodium salicylate. Toxicological Sciences 2008;104:397-404.

[10] Eyal S, Yagen B, Sobol E, Altschuler Y, Shmuel M, Bialer M. The activity of antiepileptic drugs as histone deacetylase inhibitors. Epilepsia 2004;45:737-44.

[11] Beutler AS, Li S, Nicol R, Walsh MJ. Carbamazepine is an inhibitor of histone deacetylases. Life Sciences 2005;76:3107-15.

[12] Bjerkedal T, Czeizel A, Goujard J, Kallen B, et al. Valproic Acid and spina bifida. Lancet 1982;2:1096.

[13] Robert E, Valproic. Acid and spina bifida. Lancet 1982;2:1096.

[14] Wu G, Nan C, Rollo JC, Huang X, Tian J. Sodium valproate-induced congenital cardiac abnormalities in mice are associated with the inhibition of histone deacetylase. Journal of Biomedical Science 2010;17:16-23.

[15] Detich N, Bovenzi V, Szyf M. Valproate induces replication-independent active DNA demethylation. Journal of Biological Chemistry 2003;278:27586-92.

[16] Milutinovic S, D'Alessio AC, Detich N, Szyf M. Valproate induces widespread epigenetic reprogramming which involves demethylation of specific genes. Carcinogenesis 2007;28:560-71.
[17] Szyf M. The implications of DNA methylation for toxicology: toward toxicomethylomics, the toxicology of DNA methylation. Toxicological Sciences 2011;120:235-55.

[18] Ou JN, Torrisani J, Unterberger A, Provençal N, Shikimi K, Karimi M, et al Histone deacetylase inhibitor trichostatin A induces global and gene-specific DNA demethylation in human cancer cell lines. Biochemical Pharmacology 2007;73:1297-307.

[19] Szyf M, Kaplan F, Mann V, Giloh H, Kedar E, Razin A. Cell cycle-dependent regulation of eukaryotic DNA methylase level. Journal of Biological Chemistry 1985;260:8653-6.

[20] Brunaud L, Alberto JM, Ayav A, Gérard P, Namour F, Antunes L, et al. Effects of vitamin B12 and folate deficiencies on DNA methylation and carcinogenesis in rat liver. Clinical Chemistry and Laboratory Medicine 2003;41: 1012-9.

[21] De Wals P, Tairou F, Van Allen MI, Uh SH, Lowry RB, Sibbald B, et al. Reduction in neural-tube defects after folic acid fortification in Canada. New England Journal of Medicine 2007;357:135-42.

[22] Persad VL, Van den Hof MC, Dubé JM, Zimmer P. Incidence of open neural tube defects in Nova Scotia after folic acid fortification. Canadian Medical Association Journal 2002;167:241-5.

[23] Craig J, Morrison P, Morrow J, Patterson V. Failure of periconceptual folic acid to prevent a neural tube defect in the offspring of a mother taking sodium valproate. Seizure 1999;8:253-4.

[24] Yerby MS. Clinical care of pregnant women with epilepsy: neural tube defects and folic acid supplementation. Epilepsia 2003;44(Suppl. 3):33-40.

[25] Pittschieler S, Brezinka C, Jahn B, Trinka E, et al. Spontaneous abortion and the prophylactic effect of folic acid supplementation in epileptic women undergoing antiepileptic therapy. Journal of Neurology 2008;255:1926-31.

[26] Ehlers K, Elmazar MM, Nau H. Methionine reduces the valproic acid-induced spina bifida rate in mice without altering valproic acid kinetics. Journal of Nutrition 1996;126:67-75.

[27] Padmanabhan R, Shafiullah MM. Amelioration of sodium valproate-induced neural tube defects in mouse fetuses by maternal folic acid supplementation during gestation. Congenital Anomalies 2003;43:29-40.

[28] Dawson JE, Raymond AM. Winn LM Folic acid and pantothenic acid protection against valproic acid-induced neural tube defects in CD-1 mice. Toxicology and Applied Pharmacology 2006;211:124-32.

[29] Hansen DK, Grafton TF, Dial SL, Gehring TA, Siitonen PH. Effect of supplemental folic acid on valproic acid-induced embryotoxicity and tissue zinc levels in vivo. Teratology 1995;52:277-85.

[30] Bennett GD, Ridge L, Finnell RH. Folate, vitamin B12, inositol or pantothenic acid supplementation exacerbates the frequency of valproic acid induced neural tube defects. Toxicologist 1998;42:262.

[31] Wells PG, Bhuller Y, Chen CS, Jeng W, et al. Molecular and biochemical mechanisms in teratogenesis involving reactive oxygen species. Toxicology and Applied Pharmacology 2005;207:354-66.

[32] Finnell RH, Dansky LV. Parental epilepsy, anticonvulsant drugs, and reproductive outcome: epidemiologic and experimental findings spanning three decades: animal studies. Reproductive Toxicology 1991;5:281-99.

[33] Wells PG, Kim PM, Laposa RR, Nicol CJ, Parman T, Winn LM. Oxidative damage in chemical teratogenesis. Mutation Research 1997;396:65-78.

[34] Abramov JP, Wells PG. Embryonic catalase protects against endogenous and phenytoin-enhanced DNA oxidation and embryopathies in acatalasemic and human catalase-expressing mice. FASEB Journal 2011;25:2188-200.

[35] Abramov JP, Wells PG. Embryoprotective role of endogenous catalase in acatalasemic and human catalase-expressing mouse embryos exposed in culture to developmental and phenytoin-enhanced oxidative stress. Toxicological Sciences 2011;120:428-38.

[36] Zhang B, Wang X, Nazarali AJ. Ascorbic acid reverses valproic acid-induced inhibition of hoxa 2 and maintains glutathione homeostasis in mouse embryos in culture. Cellular and Molecular Neurobiology 2010;30:137-48.

[37] Al Deeb S, Al Moutaery K, Arshaduddin M, Tariq M. Vitamin E decreases valproic acid induced neural tube defects in mice. Neuroscience Letters 2000;292:179-82.

[38] Tung EW, Winn LM. Valproic acid increases formation of reactive oxygen species and induces apoptosis in postimplantation embryos: a role for oxidative stress in valproic acid-induced neural tube defects. Molecular Pharmacology 2011;80:979-87.

[39] Schulpis KH, Lazaropoulou C, Regoutas S, Karikas GA, Margeli A, Tsakiris S et al. Valproic acid monotherapy induces DNA oxidative damage. Toxicology 2006;217:228-32

[40] Varoglu AO, Yildirim A, Aygul R, Gundogdu OL, Sahin YN. Effects of valproate carbamazepine, and levetiracetam on the antioxidant and oxidant systems in epileptic patients and their clinical importance. Clinical Neuropharmacology 2010;33:155-7.

[41] Lee CJ, Gonçalves LL, Wells PG. Embryopathic effects of thalidomide and its hydrolysis products in rabbit embryo culture: evidence for a prostaglandin $\mathrm{H}$ synthase (PHS)-dependent, reactive oxygen species (ROS)-mediated mechanism. FASEB Journal 2011;25:2468-83.

[42] Clarren SK. Recognition of fetal alcohol syndrome. Journal American Medical Association 1981;245:2436-9.

[43] Abel EL. An update on incidence of FAS: FAS is not an equal opportunity birth defect. Neurotoxicology and Teratology 1995;17:437-43.

[44] Hoyme HE, May PA, Kalberg WO, Kodituwakku P, et al. A practical clinica approach to diagnosis of fetal alcohol spectrum disorders: clarification of the 1996 institute of medicine criteria. Pediatrics 2005;115:39-47. 
[45] Schardein JL. Chemically induced birth defects. New York: Marcel Dekker, Inc.; 2001.

[46] Cohen-Kerem R, Koren G. Antioxidants and fetal protection against ethanol teratogenicity. I. Review of the experimental data and implications to humans. Neurotoxicology and Teratology 2003;25:1-9.

[47] Kotch LE, Chen SY, Sulik KK. Ethanol-induced teratogenesis: free radical damage as a possible mechanism. Teratology 1995;52:128-36.

[48] Lee RD, An SM, Kim SS, Rhee GS, et al. Neurotoxic effects of alcohol and acetaldehyde during embryonic development. Journal of Toxicology and Environmental Health Part A 2005;68:2147-62.

[49] Wentzel P, Rydberg U, Eriksson UJ. Antioxidative treatment diminishes ethanol-induced congenital malformations in the rat. Alcoholism, Clinical and Experimental Research 2006;30:1752-60.

[50] Padmanabhan R, Sreenatan RN, Singh S. Studies on the lethal and teratogenic effects of acetaldehyde in the rat. Congenital Anomalies 1983;23:13-23.

[51] Menegola E, Broccia ML, Prati M, Ricolfi R, Giavini E, Glutathione. $\mathrm{N}$-Acetylcysteine protection against acetaldehyde embryotoxicity in rat embryos developing in vitro. Toxicology In vitro 1995;9:633-41.

[52] Horvat S, Mcwhir J, Rozman D. Defects in cholesterol synthesis genes in mouse and in humans: lessons for drug development and safer treatments. Drug Metabolism Reviews 2011;43:69-90.

[53] Binns W, Thacker EJ, James LF, Huffman WT. A congenital cyclopean type malformation in lambs. Journal of the American Veterinary Medical Association 1959;134:180-3.

[54] Keeler RF, Binns W. Teratogenic compounds of Veratrum californicum (Durand). V. Comparison of cyclopian effects of steroidal alkaloids from the plant and structurally related compounds from other sources. Teratology 1968;1:5-10.

[55] Keeler RF. Teratogenic compounds of Veratrum californicum (Durand). XI. Gestational chronology and compound specificity in rabbits. Proceedings of the Society for Experimental Biology and Medicine 1971;136:1174-9.

[56] Keeler RF. Teratogenic effects of cyclopamine and jervine in rats, mice and hamsters. Proceedings of the Society for Experimental Biology and Medicine 1975;149:302-6.

[57] Gaffield W, Keeler RF. Induction of terata in hamsters by solanidane alkaloids derived from Solanum tuberosum. Chemical Research in Toxicology 1996;9:426-33.

[58] Chiang C, Litingtung Y, Lee E, Young KE, Corden JL, Westphal H, et al. defective axial patterning in mice lacking Sonic hedgehog gene function. Nature 1996;383:407-13.

[59] Roessler E, Belloni E, Gaudenz K, Jay P, Berta P, Scherer SW, et al. Mutations in the human sonic hedgehog gene cause holoprosencephaly. Nature Genetics 1996;14:357-60.

[60] Cooper MK, Porter JA, Young KE, Beachy PA. Teratogen-mediated inhibition of target tissue response to Shh signaling. Science 1998;280:1603-7.

[61] Incardona JP, Gaffield W, Kapur RP, Roelink H. The teratogenic veratrum alkaloid cyclopamine inhibits sonic hedgehog signal transduction. Development 1998;125:3553-62.

[62] Porter JA, Young KE, Beachy PA. Cholesterol modification of hedgehog signaling proteins in animal development. Science 1996;274:255-9.

[63] Irons M, Elias ER, Salen G, Tint GS, Batta AK. Defective cholesterol biosynthesis in Smith-Lemli-Opitz syndrome. Lancet 1993;341:1414

[64] Fitzky BU, Moebius FF, Asaoka H, Waage-Baudet $H$, et al. 7Dehydrocholesterol-dependent proteolysis of HMG-CoA reductase suppresses sterol biosynthesis in a mouse model of Smith-Lemli-Opitz/RSH syndrome. Journal of Clinical Investigation 2001;108:905-15.

[65] Wassif CA, Zhu P, Kratz L, Krakowiak PA, et al. Biochemical, phenotypic and neurophysiological characterization of a genetic mouse model of RSH/Smith-Lemli-Opitz syndrome. Human Molecular Genetics 2001:10:555-64.

[66] Roux C, Wolf C, Mulliez N, et al. Teratogenic action in rats of a new 7dehydrocholesterol reductase inhibitor: BM 15766. Teratology 1995;51:36.

[67] Llirbat B, Wolf C, Chevy F, Citadelle D, Bereziat G, Roux C. Normal and inhibited cholesterol synthesis in the cultured rat embryo. Journal of Lipid Research 1997;38:22-34

[68] Repetto M, Maziere JC, Citadelle D, Dupuis R, Meier M, Biade S, et al. Teratogenic effect of the cholesterol synthesis inhibitor AY 9944 on rat embryos in vitro. Teratology 1990;42:611-8.

[69] Roux C, Horvath C, Dupuis R. Teratogenic action and embryo lethality of AY 9944R. Prevention by a hypercholesterolemia-provoking diet. Teratology 1979;19:35-8.

[70] Barbu V, Roux C, Lambert D, Dupuis R, Gardette J, Maziere JC, et al. Cholesterol prevents the teratogenic action of AY 9944: importance of the timing of cholesterol supplementation to rats. Journal of Nutrition 1988;118:774-9.

[71] Dehart DB, Lanoue L, Tint GS, Sulik KK. Pathogenesis of malformations in a rodent model for Smith-Lemli-Opitz syndrome. American Journal of Medical Genetics 1997;68:328-37.

[72] Antley R, Bixler D. Trapezoidocephaly, midfacial hypoplasia and cartilage abnormalities with multiple synostoses and skeletal fractures. Birth Defects Original Article Series 1975;11:397-401.

[73] Cragun DL, Trumpy SK, Shackleton CH, Kelley RI, Leslie ND, Mulrooney NP et al. Undetectable maternal serum uE3 and postnatal abnormal sterol and steroid metabolism in Antley-Bixler syndrome. American Journal of Medical Genetics Part A 2004;129A:1-7.

[74] Keber R, Motaln H, Wagner KD, Debeljak N, Rassoulzadegan M, Ačimovič J, et al. Mouse knockout of the cholesterogenic cytochrome P450 lanosterol 14alpha-demethylase (Cyp51) resembles Antley-Bixler syndrome. Journal of Biological Chemistry 2011;286:29086-97.

[75] Vanden Bossche $\mathrm{H}$. Biochemical targets for antifungal azole derivatives: hypothesis on the mode of action. Current Topics in Medical Mycology 1985; 1:313-51.

[76] Carey JC, Martinez L, Balken E, Leen-Mitchell M, Robertson J. Determination of human teratogenicity by the astute clinician method: review of illustrative agents and a proposal of guidelines. Birth Defects Research Part A: Clinical and Molecular Teratology 2009;85:63-8.

[77] Tiboni GM, Giampietro. F Murine teratology of fluconazole: evaluation of developmental phase specificity and dose dependence. Pediatric Research 2005;58:94-9.

[78] Tiboni GM, Marotta F, Del Corso A, Giampietro F. Defining critical periods fo itraconazole-induced cleft palate, limb defects and axial skeletal malformations in the mouse. Toxicology Letters 2006;167:8-18.

[79] Menegola E, Broccia ML, Di Renzo F, Massa V, Giavini E. Craniofacial and axial skeletal defects induced by the fungicide triadimefon in the mouse. Birth Defects Research Part B Developmental and Reproductive Toxicology 2005;74:185-95.

[80] Farag AT, Ibrahim HH. Developmental toxic effects of antifungal flusilazole administered by gavage to mice. Birth Defects Research Part B Developmenta and Reproductive Toxicology 2007;80:12-7.

[81] Morris-Kay GM. Retinoic acid and development. Pathobiology 1992;60:264-70.

[82] Whiting J. Craniofacial abnormalities induced by the ectopic expression of homeobox genes. Mutation Research 1997;396:97-112.

[83] Kessel M, Gruss P. Homeotic transformations of murine vertebrae and concomitant alteration of Hox codes induced by retinoic acid. Cell 1991:67:89-104.

[84] Tabin C. The initiation of the limb bud: growth factors, Hox genes, and retinoids. Cell 1995;80:671-4.

[85] Emmanouil-Nikoloussi EN, Goret-Nicaise M, Foroglou P, Kerameos-Foroglou C, Persaud TV, Thliveris JA, et al. Histological observations of palatal malformations in rat embryos induced by retinoic acid treatment. Experimental and Toxicologic Pathology 2000;52:437-44.

[86] Pennimpede T, Cameron DA, MacLean GA, Li H, Abu-Abed S, Petkovich M. The role of CYP26 enzymes in defining appropriate retinoic acid exposure during embryogenesis. Birth Defects Research Part A 2010;88:883-94.

[87] Leonard L, Horton C, Maden M, Pizzey JA. Anteriorization of CRABP-I expression by retinoic acid in the developing mouse central nervous system and its relationship to teratogenesis. Developmental Biology 1995;168:514-28.

[88] Pullarkat RK. Hypothesis: prenatal ethanol-induced birth defects and retinoic acid. Alcoholism, Clinical and Experimental Research 1991;15:565-7.

[89] Duester G. A hypothetical mechanism for fetal alcohol syndrome involving ethanol inhibition of retinoic acid synthesis at the alcohol dehydrogenase step. Alcoholism, Clinical and Experimental Research 1991;15:568-72.

[90] Deltour L, Ang HL, Duester G. Ethanol inhibition of retinoic acid synthesis as a potential mechanism for fetal alcohol syndrome. FASEB Journal 1996:10:1050-7.

[91] Johnson CS, Zucker RM, Hunter 3rd ES, Sulik KK. Perturbation of retinoic acid (RA)-mediated limb development suggests a role for diminished RA signaling in the teratogenesis of ethanol. Birth Defects Research Part A: Clinical and Molecular Teratology 2007;79:631-41.

[92] Yelin R, Schyr RB, Kot H, Zins S, Frumkin A, Pillemer G, et al. Ethanol exposure affects gene expression in the embryonic organizer and reduces retinoic acid levels. Developmental Biology 2005;279:193-204.

[93] Van Wauwe JP, Coene MC, Goossens J, Cools W, Monbaliu J. Effects of cytochrome P-450 inhibitors on the in vivo metabolism of all-transretinoic acid in rats. Journal of Pharmacology and Experimental Therapeutics 1990;252:365-9.

[94] Schwartz EL, Hallam S, Gallagher RE, Wiernik PH. Inhibition of all-transretinoic acid metabolism by fluconazole in vitro and in patients with acute promyelocytic leukemia. Biochemical Pharmacology 1995;50:923-8.

[95] Menegola E, Broccia ML, Di Renzo F, Giavini E. Postulated pathogenic pathways in triazole fungicide dysmorphogenic effects. Reproductive Toxicology 2006;22:186-95

[96] Menegola E, Broccia ML Di Renzo F Massa V Giavini E Relationship between hindbrain segmentation, neural crest cell migration and branchial arch abnormalities in rat embryos exposed to fluconazole and retinoic acid in vitro. Reproductive Toxicology 2004;18:121-30.

[97] Tiboni GM, Marotta F, Carletti E. Fluconazole alters CYP26 gene expression in mouse embryos. Reproductive Toxicology 2009;27:199-202.

[98] Papis E, Bernardini G, Gornati R, Menegola E, Prati M. Gene expression in Xenopus laevis embryos after Triadimefon exposure. Gene Expression Patterns 2007;7:137-42

[99] Ornoy A. Valproic acid in pregnancy: how much are we endangering the embryo and fetus? Reproductive Toxicology 2009;28:1-10.

[100] Li YX, Yang HT, Zdanowicz M, Sicklick JK, Qi Y, Camp TJ, et al. Fetal alcoho exposure impairs Hedgehog cholesterol modification and signaling. Laboratory Investigation 2007;87:231-40.

[101] Aoto K, Shikata Y, Higashiyama D, Shiota K, Motoyama J. Fetal ethanol exposure activates protein kinase A and impairs Shh expression in prechordal mesendoderm cells in the pathogenesis of holoprosencephaly. Birth Defects Research Part A: Clinical and Molecular Teratology 2008;82:224-31.

[102] Dalle_Donne I, Rossi R, Colombo R, Giustarini D, Milzani A. Biomarkers of oxidative damage in human disease. Clinical Chemistry 2006;52:601-23. 